\title{
EFEITO DA ADUBAÇÃO VERDE NA CULTURA DO MILHO (Zea mays L.)
}

\author{
Maxwel Rodrigues Nascimento' \\ Mario Euclides Pechara da Costa Jaeggi ${ }^{2}$ \\ Julio Cesar Gradice Saluci ${ }^{3}$ \\ Rebyson Bissaco Guidinelle ${ }^{4}$ \\ Israel Martins Pereira ${ }^{5}$ \\ Alex Justino Zacarias ${ }^{6}$ \\ Rogério Rangel Rodrigues ${ }^{7}$ \\ Samuel Ferreira da Silva ${ }^{8}$ \\ Maurício Novaes Souza ${ }^{9}$
}

Resumo: A adubação verde consiste no cultivo de diferentes espécies vegetais em uma mesma área, em sucessão ou simultaneamente com a finalidade principal de melhorar a fertilidade do solo. Prefere-se assim, aquelas que produzam maior volume de matéria seca, estejam menos sujeitas a pragas e doenças e que possuam sementes relativamente uniformes e fáceis de semear. As plantas da família Fabaceae são as mais utilizadas na adubação verde por apresentarem elevado potencial em fixar o nitrogênio atmosférico. Objetivou-se com a realização deste trabalho elaborar uma revisão de literatura sobre o rendimento da cultura do milho em consórcio e sucessão às espécies vegetais utilizadas para adubação verde. Com base nos resultados obtidos é possível inferir que a prática da adubação verde na cultura do milho é viável, além de melhorar a fertilidade e as características físicas do solo diminui a dependência por adubos minerais.

Palavras-chave: Leguminosas; Gramíneas; Adubo verde; Milho; Consórcio.

\footnotetext{
1 Mestrado em Produção Vegetal/Universidade Estadual Norte Fluminense Darcy Ribeiro, Brasil. E-mail: maxwel.rn88@gmail.com.

2 Mestrado em Produção Vegetal/Universidade Estadual Norte Fluminense Darcy Ribeiro, Brasil. E-mail: mariopechara@hotmail.com.

3 Teconologia em Cafeicultura/Instituto Federal do Espírito Santo campus Alegre, Brasil. E-mail: juliosaluci@gmail.com.

4 Teconologia em Cafeicultura/Instituto Federal do Espírito Santo campus Alegre, Brasil. E-mail: rebysonguidinelle@gmail.com.

5 Teconologia em Cafeicultura/Instituto Federal do Espírito Santo campus Alegre, Brasil. E-mail: israelmartins80@gmail.com.

6 Teconologia em Cafeicultura/Instituto Federal do Espírito Santo campus Alegre, Brasil. E-mail: alexjustino12@gmail.com.

7 Doutorado em Engenharia Agrícola/Universidade Federal de Lavras, Brasil. E-mail: rogeriorr7@hotmail.com.

8 Doutorado em Produção Vegetal/Universidade Federal do Espírito Santo, Brasil. E-mail: samuelfd.silva@yahoo.com.br.

${ }^{9}$ Professor/Instituto Federal de Educação, Ciência e Tecnologia do Espírito Santo campus Alegre, Brasil. E-mail: mauriciosnovaes@yahoo.com.br.
} 